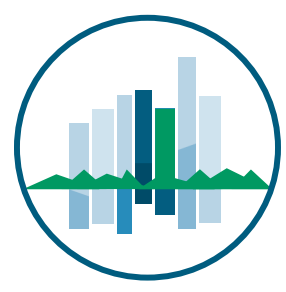

True Smart and Green City? 8th Conference of the International Forum on Urbanism
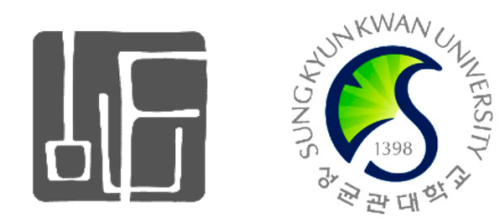

Conference Proceedings Paper

\title{
Beyond the Greenways: A People-Centered Urban Planning and Design Approach for Shenzhen, the 'World Factory' in Transition
}

\author{
Lei Qu *, Bang Fu and Luisa Calabrese \\ Department of Urbanism, Faculty of Architecture and the Built Environment, Delft University of \\ Technology, Julianalaan 134, 2628 BL Delft, The Netherlands \\ * Author to whom correspondence should be addressed; Tel: +31(0)639251224; \\ E-mail: L.Qu@tudelft.nl
}

\begin{abstract}
Greenway as landscaped, linear and multi-purpose component of urban planning has been increasingly used globally, especially in cities experiencing de-industrialization process. It has the potential to restructure city regions and improve connectivity of public spaces, making cities greener and friendlier to pedestrians and cyclists. There is no doubt that greenway could be seen as a tool of planning and design for creating green cities. However, without considering the specific demands of people who are the daily users of green spaces, this tool might not lead to truly green cities that people living in it appreciate. This paper is proposing a people-centered approach for planning and design of greenway systems, with the focus of transforming newly industrialized areas into liveable cities for local residents. The context of this paper is Shenzhen (China), known as the 'world factory', which is currently in the transitional period towards a 'world city'. The authors will present an integrated greenway system proposal for Dalang, a peri-urban district of Shenzhen. It takes into account the daily lives of local residents (young migrant workers) and their demands on urban nature spaces. It is expected that with such a people-centered approach, bio-diversity, urban amenity and social interaction could be enhanced simultaneously.
\end{abstract}

Keywords: Greenway system, urban nature space, social interaction, Shenzhen 


\section{Introduction: City and nature}

With the world more and more urbanized, meeting human needs in the urban context is a key task of urban planning and design. As urbanization is increasingly threatening the availability of nature and biodiversity within urban areas, concern over the vital role of nature in enhancing well-being of people is essential (Matsuoka and Kaplan, 2008). The existing urban nature is therefore valuable, with the potential to maintain biodiversity of the built environment, and meet social demands of contacting with nature. The origin of urban nature can be roughly classified into three categories: 'relict' nature, 'manmade' nature and 'spontaneous' nature. 'Relict' nature refers to relatively well preserved nature left between or inside built-up areas; 'man-made' nature is mainly about the built parks, gardens and restored nature; 'spontaneous' nature is usually seen in ruderal sites in urban areas. Urban green areas from all these three categories provide opportunities for people to contact with nature, especially the nearby residents (Yli-Pelkonen and Niemelä, 2005).

Greenways, consisting all these three categories of nature, have long played a significant role in the development of urban and sub-urban areas. They could help to mitigate the loss of 'natural' space in urban settings, provide scenic qualities as well as recreational functions, and preserve the natural habitat. Such multipurpose greenways usually involve every city scales and planning levels, ranging from neighborhood to city and region (Fábos, 2004). Looking back into history, greenways were originally amenity oriented, developed to address aesthetic and recreational needs of city dwellers. Since the second half of the $20^{\text {th }}$ century, greenways started to play a role in reacting to the problems of the built environment caused by industrialization, improving urban qualities with, for instance, non-motorized green corridors. However, it wasn't until the late 1980s that broader spectrums of objectives were addressed, like preserving natural habitat and cultural resources (Zakaria El Adli Imam, 2006).

In the past decades, China has been experiencing rapid and extensive urbanization. Greenways have been planned systematically and extensively across the nation. However, the planning and design of greenways is still with limited perspectives. In China, greenway has a long history as an essential component of traditional urban planning, contributed greatly to harmonious urban-nature relationship. While the modern greenway planning, as part of the urban green space system planning originated since 1950s, emphasizes very much on quantity of green space than quality of place. In urban planning practices, planners have to meet rigid regulations on green space indexes, such as park area per capita, green space ratio and so on (Wang, 2009). Affected by such over-emphasis on quantitative indexes, qualities of green spaces are not fully explored. For instance, urban nature space that is close to local residents and maintaining biodiversity is largely overlooked in current planning. In the past decades, greenways were mainly planned for the purpose of hazard alleviation in countryside. Only in recent years, greenway network planning started to include recreational functions in the city-regional levels. However, it does not involve green spaces in the neighborhood scale, which could bring nature to the daily lives of people, create sense of community and formulate identity of place. Besides, greenways are developed as 'man-made' nature, with planning concepts focusing very much on 'beautification'. For examples, streams and rivers in both urban and rural areas are very often dammed, channelized and lined with concrete; native trees and plants are sometimes replaced with exotic trees and ornamental flowers (Yu et al., 2006). These approaches will have negative impacts on bio-diversity and ecological sustainability of cities and regions. This paper aims at contributing to the discussion on greenway system 
planning and design in Chinese cities, by bringing in concerns on urban ecological and social systems, especially the benefit of local people at the neighborhood level.

\section{Greenway system planning vs. urban ecological and social systems}

As mentioned above, greenways could be considered as ecological corridors, linking fragmented urban nature spaces with multiple urban functions, which results into a greenway system. Since these green spaces are also part of the open public space system, the intense interaction between urban ecological and social systems made it necessary to take social demands into account when studying the greenway system. In this sense, what kinds of green spaces are needed by nature (maintaining biodiversity) and by society (meeting social demands) (Yli-Pelkonen and Niemelä, 2005)? While biodiversity is getting more and more attention in greenway system planning, especially in city and regional scales, there isn't much comprehensive understanding yet on social demands of contacting with nature in the neighborhoods scale.

The presence of nature within built environment could not only meet people's aesthetic and recreational demands, but also enhance the well-being of people. Interactions with natural spaces can get people relaxed and restored psychologically, especially in urban areas where life is stressful and access to nature is relatively limited (Gobster and Westphal, 2004). Besides, with its associated recreational functions like walking, jogging, cycling, and hiking etc., urban nature space may facilitate interaction among people, and create the sense of community and identity of place.

These above-mentioned social needs embedded in the demands of contacting with nature could be met with diverse urban green spaces, ranging from urban forests to pocket parks and roof gardens, and varying from derelict land with vegetation, to naturalistic and designed landscape. Comparing to all the others, the nearby residents benefit the most from urban nature spaces, as they tend to use such spaces more often in their daily lives, especially when these spaces are available in residential settings, at workplaces, and with public facilities. This has confirmed that both needs of nature and society are essential in greenway system planning, especially in the local scale (Matsuoka and Kaplan, 2008).

\section{Examples of greenway planning in highly urbanized areas}

To mitigate the loss of 'natural' space caused by urbanization, and meet the social needs of contacting with nature in daily lives of local residents, the challenge of greenway planning is dealing with the competing land uses for urban nature, economic development, and high-density urban living. Within highly urbanized built environment, how to make use of the existing urban nature spaces, create new green areas and connect the fragmented sites are the main questions to be answered in the strategic planning for greenway network. This involves spatial interventions supported by common interests of stakeholders.

In recent years, there appeared quite some good practice of urban regeneration projects, with similar ideas of transforming the existing outdated urban infrastructure/space into (part of the) greenways, which could improve the quality of place and restructure the city simultaneously. Two of the examples from the United States are the High Line in New York and the Atlanta Belt Line. The High Line is a public park built on a historic freight rail line elevated above the streets on Manhattan's West Side. It is owned by the City of New York, maintained and operated by 'Friends of the High Line', which is a non-profit 
conservancy founded by community residents, "fought for the High Line's preservation and transformation at a time when the historic structure was under the threat of demolition" (www.thehighline.org). Currently it offers free and low-cost public programs, including talks, films, performances, tours, and family activities (www.thehighline.org). This project shows positive contribution of greenways to the transformation of the old urban fabrics, from both social and ecological perspectives. The other example of Atlanta Belt Line is "a redevelopment project that will provide a network of public parks, multi-use trails and transit along a historic 22-mile railroad corridor circling Atlanta downtown and connecting many neighborhoods directly to each other" (www.beltline.org). Atlanta BeltLine, Inc. (ABI) manages the planning, design and implementation of the project with partners in the public and private sectors. Funding for the Atlanta BeltLine project comes from a combination of federal, state, local, and private sources (www.beltline.org). This project will have impacts on a larger range of scales than the High Line project. Therefore it has generated common interests from a wider range of stakeholders, and became a long-term vision for the city. Nevertheless, the benefits for the local residents are well integrated in this large-scale project, in terms of liveability and accessibility by public transportation.

At the policy level, Singapore could be seen as a showcase on greenway planning through land management. Singapore has achieved a Garden City ambience with a greenway network connecting a series of parks within the scales of city and neighborhoods. Such greenway network was named as park connector network. A key challenge in implementing the park connector network in Singapore is to ensure connectivity among branches of the greenways. Besides, park connectors may run through residential areas, providing direct connections with nature as well as non-motorized routes for local residents. To achieve such goals, acquisition of land is the biggest obstacle. Generally speaking, there are two ways that land may be secured for greenway projects in Singapore: 1) Land is re-zoned as Parks \& Gardens; 2) Land is "borrowed" by the National Parks Board from other land owners (e.g. land owned by housing or transportation sectors) (Tan, 2006). For examples, to achieve connectivity among greenway branches, road reserves and additional public land could be used; when greenways run into the neighborhoods, the National Parks Board might need to borrow land from housing sectors. Land management in combination with strategic partnerships has become the characteristics of the greenway planning in Singapore (Tan 2006). As a highly urbanized city-state, the experience of Singapore could be seen as a showcase of strategic greenway planning in coping with conflicts of land uses and interests, which is especially relevant to rapidly urbanizing cities seeking for a new 'green city' profile.

\section{A world factory in transition: the case of Dalang}

\subsection{Socio-spatial conditions in Dalang}

Shenzhen, known as the world factory, has experienced 30 years of rapid urban development. Its central urban area, namely the special economic zone (SEZ) was planned with Singapore and Hong Kong as role models. Its green system, including green open spaces and boulevards, was well developed and made the central urban area of Shenzhen a liveable place. However, the peri-urban areas outside the special economic zone have experienced mainly a process of rural industrialization, which has resulted in vast spontaneous development of factories and urban villages. The district of Dalang perhaps could 
be seen as a typical example of how rural industrialization has shaped countryside into peri-urban areas in Shenzhen.

Dalang is located right outside the boarder of the special economic zone of Shenzhen (Figure 1). It is a spontaneously developed area accommodating many township enterprises, which produce mainly clothes, shoes and electronic products. During the last 30 years, Baoan district, where Dalang is part of, was influenced largely by the influx of foreign direct investment, mainly in export-oriented industries, and developed dramatically (Sit and Yang, 1997). Within this context, Dalang has transformed from a green field into an industrial area dominated by manufacturing industries. Such urbanization process driven by spontaneous development has had great impact on natural environment (Figure 2). Currently it has around 500.000 inhabitants of which $98 \%$ of them are young migrant workers from other regions in China, working on production lines.

Figure 1. Location of the Dalang district in Shenzhen (Fu, 2014).

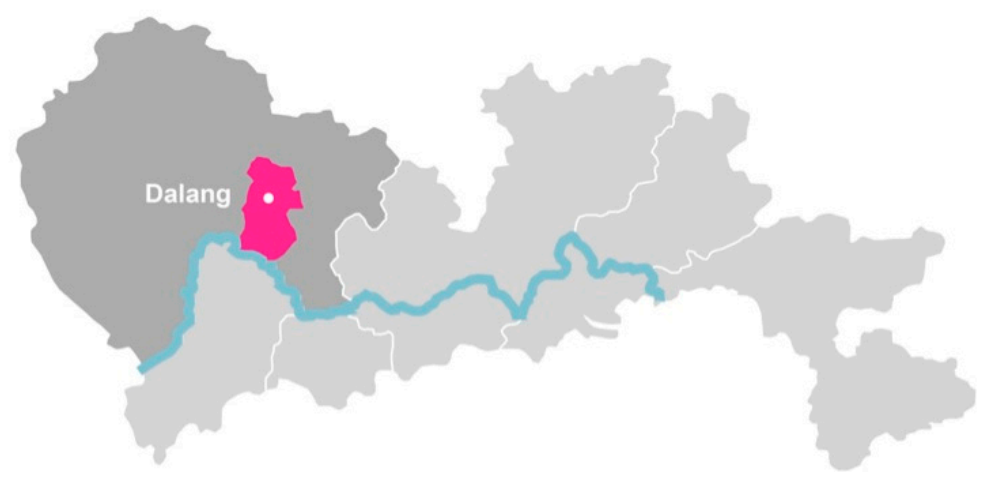

Figure 2. Transformation of Dalang in the past decades (left: NASA Goddard Space Flight Center, 1990; right: Google Maps, 2013).
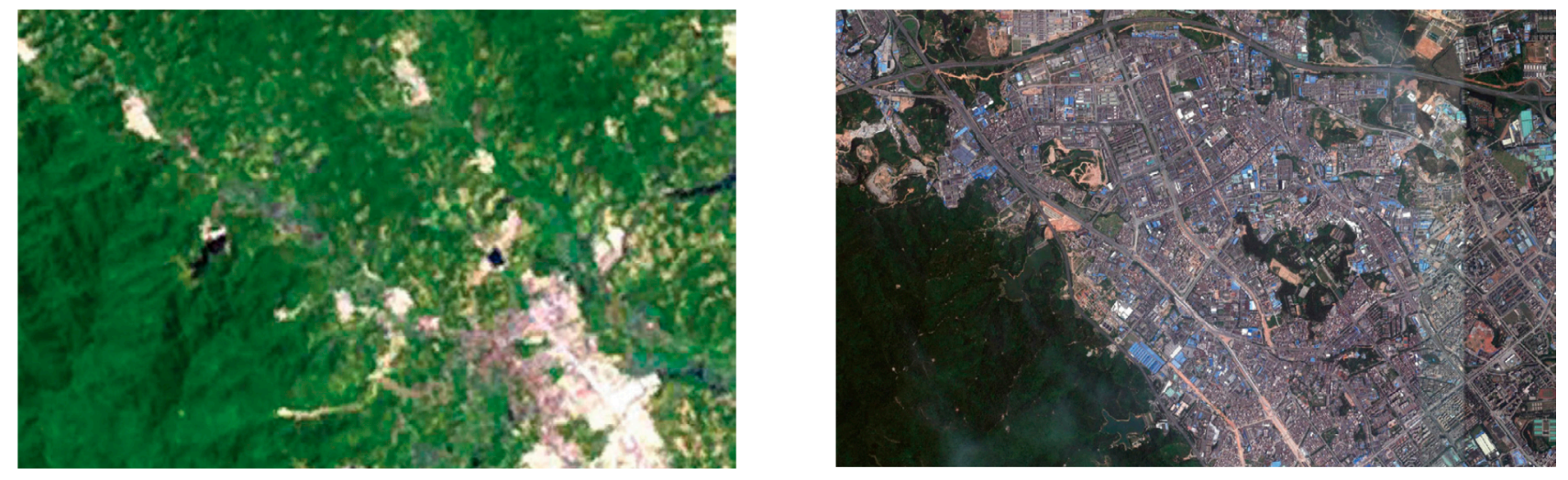

The rural urbanization process in Dalang was accompanied by an extensive expansion of 'urban villages', which were created along with land acquisition. These urban villages are enclaves built and managed by individual villagers and village collectives, providing rental housing for migrant workers working in the factories. For indigenous villagers, such rental housing is substantial means of income generation. Due to absence of formal planning regulations, the construction and maintenance of urban villages were mainly self-organized. In order to maximize income, villagers have built high-density compact apartment blocks of 6-8 floors in average, with narrow alleys between buildings (Liu et al., 
2010). Because of insecure property rights, villagers tend to avoid long-term investments and lack motivation to improve the physical condition of their properties. Therefore urban villages are often associated with negative images of overcrowded neighborhoods having social problems such as crime and conflicts.

'Urban village' in Shenzhen is mentioned in the book of Doug Saunders (2010) as one type of informal settlements functioning as 'arrival city' for migrants, providing them chances to get into the city life. In the case of Dalang, a majority of the population lives in urban villages. How to improve such a built environment for migrant workers is a key question to be answered in urban planning. The challenge here is the high-density built environment, where space for intervention is extremely lacking, especially in the neighborhood level. Inspired by the experiences of the highly urbanized American cities and the city-state of Singapore, greenway system perhaps could be used as an effective instrument to enhance liveability in Dalang. Small-scale interventions would play essential roles in reframing the urban-nature relationship and facilitating social interaction in this case.

\subsection{Greenway network in Dalang}

As a newly industrialized area, Dalang has very limited urban nature space, especially within the district. The greenway network in Dalang mainly involves a small part of the city-regional greenway system of Shenzhen that runs along the boarder of the district. As shown in Figure 3, Dalang is situated in between two major national parks, one to the Northeast and the other to the Southwest. According to the master plan of Shenzhen, a greenway network of this city region is planned, with 285,000 meters' green lines serving 5,450,000 people in total. The entrances of No. 5 and No. 2 green lines are the only points connecting Dalang with these two National parks.

Figure 3. The city-regional greenway network in Shenzhen with two entrances in Dalang (left: Guangdong Provincial Housing and Urban-Rural Construction Department, 2010; right: Fu, 2014).
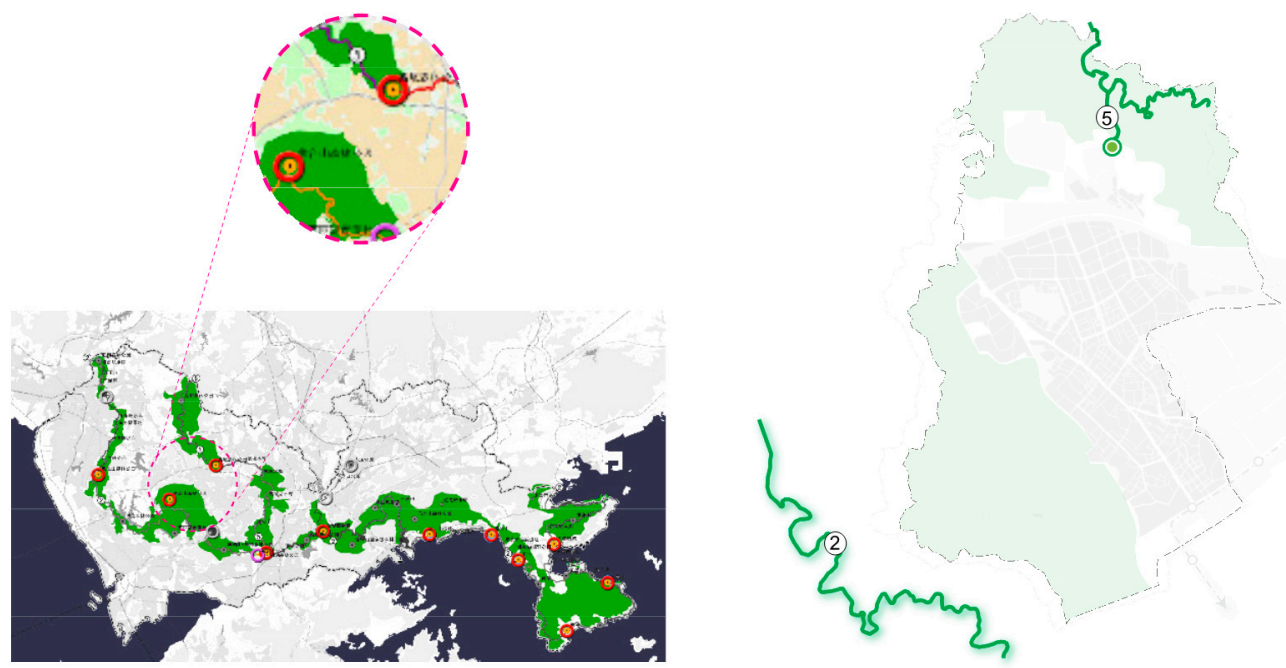

Besides a small number of parks, urban nature spaces inside Dalang are hardly seen and fragmented, mainly exist as 'leftover green space' being eaten up by the spontaneous urban development. For 
instance, although Shenzhen has announced a 100\% urbanization rate, there are still some temporary farms in and around Dalang. These are mainly vacant spaces took over by the migrants who came from countryside and used for urban farming. As long as new development happens, such temporary farms will be transformed into urban areas in no time. There are also canals inside Dalang, which are neither 'green' nor accessible by pedestrians. Generally speaking, urban villages, factories, industrial parks and some emerging shopping areas are the main components of urban fabrics in Dalang. There is hardly any space for nature within the current urban setting.

\subsection{A world factory in transition}

Such spatial conditions in Dalang are still with the characteristics of a 'world factory', where productivity is more visible than liveability in the built environment. Currently Shenzhen as a whole is transforming from a 'world factory' to a 'world city', with spatial development strategies focusing on urban regeneration of the 'three old' areas, namely old factory areas, old villages, and old residential areas. The intension is to replace the old urban form and functions at strategic locations, while at the same time restructure the whole territory, seeking for a better-connected city region, with new space and urban image for high-end economies and well-educated population. This has led to large-scale urban regeneration projects that function mainly at the city-regional level. For example, the new fashion industry valley is being constructed in the north part of Dalang, upgrading the clothing industry, one of the most productive industries in Dalang, into fashion design and related industries. Besides, a roadwidening project is also being implemented in Dalang, to improve the connectivity of road network within the district. However, with the aim of 'transforming' the current socio-economic and spatial conditions, these projects didn't take into account social demands of the existing population on liveability in the neighborhood level, not to mention the need of contacting with nature in the daily lives of people.

Talking about the social demands of local people, here we are mainly referring to the $98 \%$ of the current population of Dalang, the young migrant workers living in urban villages, working 10 hours' a day on the production lines. The stressful living and working environment made it even more desirable for these people to get relaxed and psychologically restored during their spare time. Nature, in this case, is of great importance to the nearby residents for daily recreation. While having activities within urban nature, people also get the chance to make social contact. Such interaction between social and ecological systems is very relevant to the case of Dalang. For example, the Yangtai Mountain, one of the two national parks near Dalang, has become a major recreational area where the young migrant workers go hiking very often during weekends (Mostly they go with big groups, organized by NGOs). Such activities could help the migrant workers to get recovered from stress psychologically and enlarge their social networks at the same time. Another example is the bicycle routes created by cyclist groups of the migrant workers. These routes usually connect existing greenways and the newly broadened roads near green spaces and waterways. The cyclists regularly go for bicycle tours in groups to experience nature and 'club' life, which is a new lifestyle enjoyed very much by the young migrant workers. These two examples could reflect an endogenous transition in society that the young generation of migrants is keen to adapt themselves to the changing urban environment. This might support an argument for spatial 
strategies, namely greenway planning and design in the case of Dalang, with existing population as the target group.

\subsection{An integrated greenway system for Dalang}

The rapidly changing global and local urban issues require a framework with equally complex and multi-scale approaches to deal with both current conditions and future possibilities (Mostafavi, 2011). Greenway system could be seen as such a framework, which varies greatly in scale, from narrow ribbons of green space that run through urban, suburban, and rural areas to wider corridors that incorporate diverse natural, cultural, and scenic features. Besides, it reacts to short-term demands as well as longterm sustainability. By connecting fragmented open nature spaces, greenway system facilitates people to move in and around neighborhoods in a natural setting. It may integrate diverse urban functions, while providing aesthetic experiences. Furthermore, greenway system linking suitable patches of habitat is a promising strategy to maintain bio-diversity (Ahern, 1995).

Based on such discourse, the authors proposed an integrated greenway system for Dalang, with greenways connecting and improving multi-functional urban nature spaces for migrant workers. It involves various scales of the city, district and neighborhood, with slow-traffic routes as the 'net', and urban nature spaces as the 'nodes'. As part of the complexity urban systems, such greenway system contributes to social, economic and environmental sustainability at various scale levels, with characteristics of people-centered approach (Figure 4).

Figure 4. Planning concepts of an integrated greenway system in Dalang (Fu, 2014).

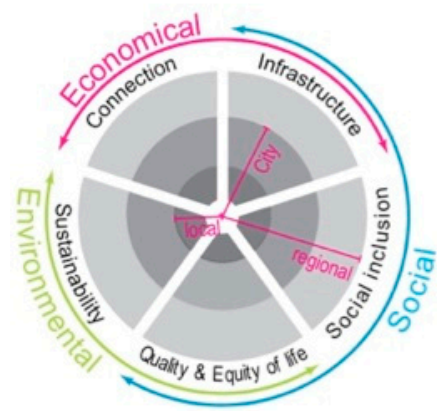

\section{Complex urban systems}

- a multi-disciplinary and cross-scale model

- people-centered approach

-considering the complexity of urban systems

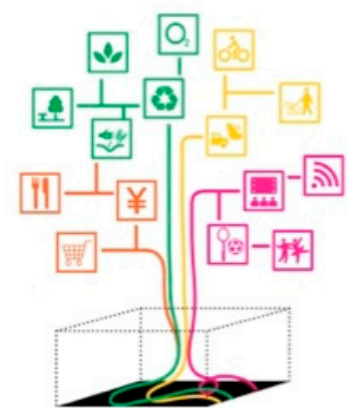

Multi-functional land use

- adaptability to various urban factions

- to meet the diverse human needs of contacting with nature

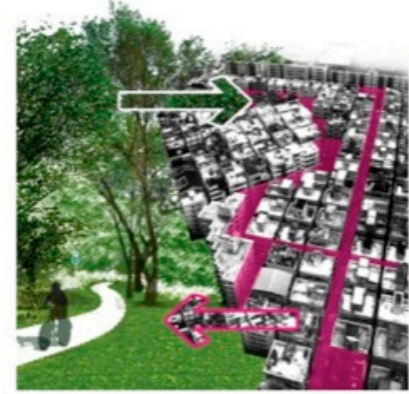

High efficiency of land use

- to make use of deserted spaces for urban nature

- to integrate fragmented public spaces for high efficiency of land use

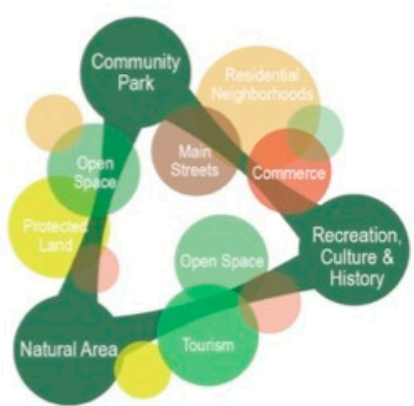

A network of open spaces

- a tool for social bonding

- to enhance bio-diversity and social interaction within urban environment.

- to enhance local identity 
Besides green routes, the main components of the greenway system also include public transportation, public spaces and public facilities. As shown in Figure 5 and 6, the correlated planning proposals suggest to:

- establish a preliminary greenway network, by connecting existing green routes (e.g. waterways, green corridors, etc.) and slow-traffic routes (in combination with the Road Widening Project);

- enhance accessibility to the greenway network by public transportation, allocating transit nodes (between fast and slow traffics) along the existing public transportation routes (e.g. metro lines, bus lines, etc.);

- make use of vacant spaces in both urban villages and industrial areas to create a public space network, by adding vegetation and diverse urban functions to such places, and connecting these scattered spaces in the compact urban areas;

- develop secondary road networks within neighborhoods as non-motorized green routes, and improve accessibility for pedestrians and cyclists to local public facilities like schools, shops, and public transportation nodes etc., where more green spaces will be created to meet migrants' needs of contacting with nature in their daily lives.

Figure 5. Main components of an integrated greenway system in Dalang (Fu, 2014).

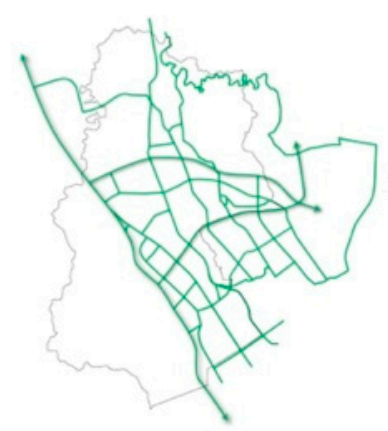

- a greenway network

With existing greenways and new green routes (to be constructed by the Road Widening Project), a preliminary greenway network could be formulated

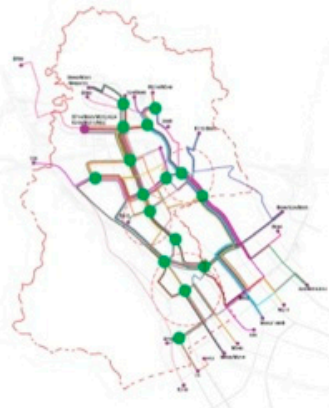

- public transit nodes

Along the existing public transportation routes, transit hubs could be allocated, for a better connection with the greenway network that covers the entire district

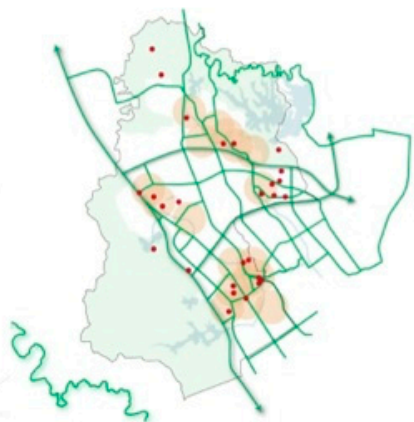

- public spaces

Vacant spaces in neighborhoods could be reused to create public space network, by adding urban nature, diverse urban functions and connecting these spaces

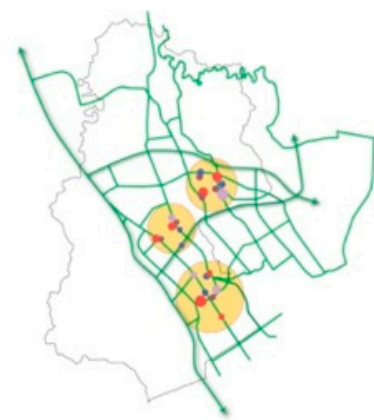

- public facilities

The greenway network could help to improve accessibility to public facilities, for local residents to contact with nature in daily lives

These planning proposals are not 'blueprint master plans', but strategic greenway planning that involves visions and actions to be taken by stakeholders. Since Dalang district is located at the periurban area of Shenzhen, urban (re-)development pressure it encountered is much less than that inside the special economic zone, while the concern of local district government on social demands and well-being of the migrant workers is very strong. Although there is very limited space available in Dalang to add public space or public facilities in the existing urban fabrics, the local district government still managed to build community centers with culture/ sport facilities and green spaces, using vacant land inside urban villages. These small-scale projects were implemented as collaboration between government and the village collectives, which has benefited a great number of migrant workers living in urban villages. The 
authors' proposal of integrated greenway system could help to enhance the quantity, quality and connectivity of such multi-functional public spaces scattered inside the neighborhoods, with added value of improving bio-diversity of the built environment.

\section{Conclusions}

Greenway is not a new phenomenon. Looking back into history of greenway planning, there is a tendency that planning concepts would shift from formulating aethetic and recreational green corridors in the city-regional scale to creating multi-functional greenway system connecting urban nature spaces across scales. The system may involve various types of green spaces ranging from regional ecological corridors, city parks to community gardens in the neighborhoods, facilitating broad spectrums of activities like culture, leisure, sports and education. Besides, more and more concern on greenway planning is about social needs of contacting with nature in the daily lives of people and bio-diversity of the built environment, both of which could contribute to a healthier urban-nature relationship.

Urban nature space, other than 'man-made' green space, could play a better role in maintaining biodiversity and meeting the social demands of contacting with 'real' nature within city, although both of them could become recreational areas for local residents. Social needs embeded in the demands of contacting with nature include amenity of the green space, psychological restoration from stress, social interaction, sense of community, and identity of place, etc. Here we are referring to the nearby residents, who benefit the most from urban nature spaces, since they tend to use such spaces more often than the passers-by. To meet the social needs of these people, it is wise to strategically allocate urban nature spaces close to places where daily lives of people happen, namely living areas, work places, public facilities, etc.

In China, greenway has a long history in tradtional urban planning, contributed greatly to the hamonious urban-natue relationship. The modern greenway planning however focuses mainly on regional corridors and quantitative indexes, but not the potential of urban nature spaces in maintaining biodiversity of the urban environment, and meeting the social needs of people in their daily lives. Dalang is such an example located in the peri-urban area of Shenzhen in the Pearl River Delta region. It experienced extensive rural industrialisation and spontaneou development in the past three decades, with the consequence of high-density built-up areas lacking of urbanity and liveability, and damaged urbannature relationship. Currently, Shenzhen as a whole is in the transitional period from 'world factory' to 'world city', which means economic transition from labor intensive to knowledge based industries, changes in social structure accordingly, as well as restructuring and upgrading of the urban fabrics. Dalang, with an existing population of which $98 \%$ is young migrant workers working on production lines, will experience dramatic changes in socio-economic conditions and the built environment. Regarding the current population, an endogenous transition in society is seen in Dalang that the young generation of migrants is keen to adapt themselves to the changing socio-economic environment and seek for better quality of lives. In this case, an integrated greenway system connecting multi-functional urban nature spaces (using vacant spaces inside neighborhoods) may help to meet the social needs of the migrant workers. Such people-centered approach of greenway planning is meaningful in rapidly urbanizing areas where a balanced urban-nature relationship is in urgent need, especially in the neighborhood level. 
Figure 6. Planning proposals of an integrated greenway system in Dalang (Fu, 2014).
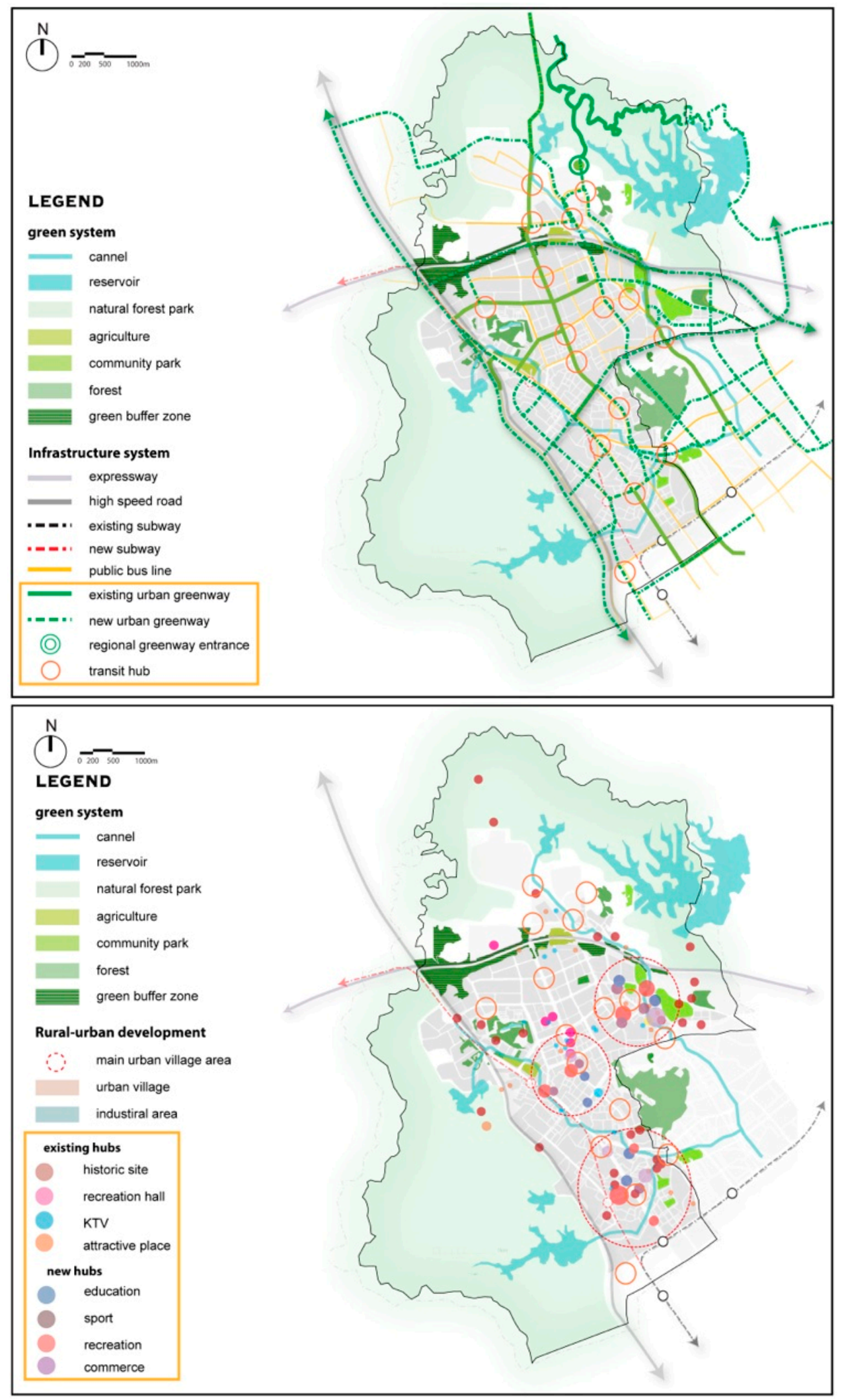

\section{Acknowledgements}

This paper is based on the work of the 'Shenzhen Scenarios' Graduation Studio at the Department of Urbanism, Faculty of Architecture and the Built Environment, Delft University of Technology. This 
studio is part of the international multi-disciplinary research program 'New New Towns' organized by the International New Town Institute (INTI). The authors thank the support of INTI and the local partner China Development Institute (CDI) on our field study in Dalang.

\section{Conflict of Interest}

The authors declare no conflict of interest.

\section{References:}

1. Ahern, J. (1995) Greenways as a planning strategy. Landscape and Urban Planning, 33: 131-155.

2. Fábos, J. G. (2004). Greenway planning in the United States: its origins and recent case studies. Landscape and Urban Planning 68(2-3): 321-342.

3. Fu, B. (2014) Greenway--connecting a livable human settlement for migrant workers in rural-urban fringe area, Master thesis, Delft University of Technology

4. Gobster, P. H. and L. M. Westphal (2004). The human dimensions of urban greenways: planning for recreation and related experiences. Landscape and Urban Planning 68(2-3): 147-165.

5. Liu, Y., He, S., Wu, F. and Webster, C. (2010) Urban villages under China's rapid urbanization: Unregulated assets and transitional neighbourhoods. Habitat International, 34: 135-144.

6. Matsuoka, R. H. and R. Kaplan (2008). People needs in the urban landscape: Analysis of Landscape And Urban Planning contributions. Landscape and Urban Planning 84(1): 7-19.

7. Mostafavi, M. (2011) Why Ecological Urbanism? In: Mostafavi, M. and Doherty, G. (eds.) Ecological Urbanism, Harvard University Lars Miller Publisher.

8. Saunders, D. (2010) Arrival City: How the Largest Migration in History is Reshaping Our World, Pantheon Books, New York.

9. Sit, V. and Yang, C. (1997) Foreign-investment-induced exo-urbanisation in the Pearl River Delta, China. Urban Studies, 34, 647-677

10. Tan, K. W. (2006). A greenway network for singapore. Landscape and Urban Planning 76(1-4): 45-66.

11. Wang, X.-J. (2009). Analysis of problems in urban green space system planning in China. Journal of Forestry Research 20(1): 79-82.

12. Yli-Pelkonen, V. and J. Niemelä (2005) Linking ecological and social systems in cities: urban planning in Finland as a case. Biodiversity and Conservation 14(8): 1947-1967.

13. $\mathrm{Yu}, \mathrm{K}$., et al. (2006). The evolution of Greenways in China. Landscape and Urban Planning 76(14): 223-239.

14. Zakaria El Adli Imam, K. (2006) Role of urban greenway systems in planning residential communities: a case study from Egypt. Landscape and Urban Planning 76(1-4): 192-209.

(C) 2015 by the authors; licensee MDPI and IFoU, This article is an open access article distributed under the terms and conditions of the Creative Commons Attribution license. 